\title{
Asymmetric optic nerve sheath diameter as an outcome factor following cranioplasty in patients harboring the 'syndrome of the trephined'
}

\author{
Assimetria do diâmetro da bainha do nervo óptico como fator prognóstico após \\ cranioplastia em pacientes portadores da 'síndrome do trefinado'
}

Antonio Santos de Araujo Junior ${ }^{1}$, Pedro Alberto Arlant ${ }^{1}$, Arnaldo Salvestrini Jr ${ }^{1}$, Carlos Eduardo Altieri², Jasper Guimarães Santos², Lauro Figueira Pinto², Mirella Martins Fazzito², Hae Won Lee²,

Luis Felipe de Souza Godoy ${ }^{3}$

\begin{abstract}
Decompressive craniectomy (DC) is gaining an increasing role in the neurosurgical treatment of intractable intracranial hypertension, but not without complications. A rare complication is the "syndrome of the trephined" (ST). It occurs when the forces of gravity overwhelm intracranial pressures, leading the brain to become sunken. Objective: To determine the usefulness of asymmetric optic nerve sheath diameter (ONSD) as an outcome factor after cranioplasty. Method: We followed-up 5 patients submitted to DC and diagnosed with ST. All were submitted to brain MRI to calculate the ONSD. Results: Only two patients presented an asymmetric ONSD, being ONSD larger at the site of craniectomy. Surprisingly these patients had a marked neurological improvement after cranioplasty. They became independent a week after and statistically earlier than others. Conclusion: It is presumed that the presence of an asymmetric ONSD in trephined patients is an independent factor of good outcome after cranioplasty.
\end{abstract}

Keywords: decompressive craniectomy, syndrome of the trephined, optic nerve.

\section{RESUMO}

A craniectomia descompressiva (CD) tem papel fundamental no tratamento da hipertensão intracraniana refratária, mas não é isenta de complicações. Uma complicação rara é a "síndrome do trefinado" (ST). Ela ocorre quando as forças gravitacionais se sobrepõem à pressão intracraniana. Objetivo: Determinar a utilidade do diâmetro da bainha do nervo óptico (DBNO) como fator prognóstico após cranioplastia. Método: Foram acompanhados 5 pacientes trefinados portadores da ST. Estes pacientes foram submetidos à ressonância magnética com medida do diâmetro da bainha do nervo óptico (DBNO). Resultados: Dois pacientes apresentaram uma assimetria do DBNO, sendo o diâmetro maior do lado craniectomizado. Para nossa surpresa estes evoluíram melhor do que os que apresentavam o DBNO simétrico. Estes pacientes se tornaram independentes uma semana após, e estatisticamente mais cedo do que os outros. Conclusão: Há evidências de que a assimetria do DBNO sirva como fator de bom prognóstico após cranioplastia no pacientes portadores da ST.

Palavras-chave: craniectomia descompressiva, síndrome do trefinado, nervo óptico.

Decompressive craniectomy is gaining an increasing role in the neurosurgical treatment of intractable intracranial hypertension in patients with head injury, acute stroke, and severe brain edema ${ }^{1-3}$.
Though technically straightforward, the procedure is not without significant complications ${ }^{2-5}$. Herniation through the cranial defect, seizures and subdural effusion are common early complications after decompressive craniectomy, whilst

${ }^{1}$ Neurocirurgião, Hospital Sírio-Libanês, Sao Paulo SP, Brazil;

${ }^{2}$ Neurologista, Hospital Sírio-Libanês, Sao Paulo SP, Brazil;

${ }^{3}$ Neurorradiologista, Hospital Sírio-Libanês, Sao Paulo SP, Brazil.

Correspondence: Antônio Santos de Araújo Júnior; Rua Peixoto Gomide 515 / cj 96 / Cerqueira César; 01409-001 São Paulo SP - Brasil;

E-mail:dr.antonioaraujojr@gmail.com

Conflict of interest: There is no conflict of interest to declare.

Received 26 February 2013; Received in final form 20 June 2013; Accepted 27 June 2013. 
hydrocephalus is the most common late complication ${ }^{2,3}$. Others rare late complications are sinking skin flaps, paradoxical herniation and external brain tamponade $e^{6,7}$.

During the late phases of recovery, patients may develop a new cognitive, neurological, or psychological deficit termed "syndrome of the trephined" (ST) ${ }^{5}$. This syndrome clinically may include dizziness, tinnitus, orthostatic headaches ${ }^{8}$, central sleep apnea ${ }^{7}$, dysarthria, limb rigidity, parkinsonian levodopa-resistant tremor, diplopia (abducens nerve palsy) ${ }^{9,10}$, reversible monoparesis ${ }^{11}$, fatigue and fluctuating levels of consciousness up to coma states ${ }^{7-10}$. It may occur following a unilateral craniectomy or a bilateral bifrontal craniectomy ${ }^{13}$.

Increasing the intracranial pressure by placing the patient into Trendelenburg position or increasing hydration may reverse the symptoms ${ }^{7,12}$. However up to now there is no clinical or radiological signal responsible to the diagnosis of the "syndrome of trephined".

In some patients harboring the ST, sinking skin flaps, paradoxical herniation and external brain tamponade may be seen $^{6}$. Paradoxical herniation consists of brain midline shift up to the contralateral side from the craniectomy, easily visualized by head CT or brain MRI, and may suggest the diagnosis.

Cerebral blood flow changes, the effect of the atmospheric pressure on the brain, as well as cerebrospinal fluid (CSF) hydrodynamic changes have been postulated as the possible reasons for this syndrome ${ }^{14,15}$. A moderate increase in venous outflow as well as a two-fold increase in craniocaudal cerebrospinal fluid systolic flow velocity has already been measured after the skull closure, reaffirming the hydrodynamic hypothesis ${ }^{15}$.

\section{METHOD}

We followed-up 5 patients submitted to decompressive craniectomy, secondary to head injury or acute stroke, up to 6 months postoperatively, among whom was noted altered levels of consciousness, sinking skin flap at the site of craniectomy, or paradoxical herniation. All patients were operated from 2008 to 2012 at our hospital by the same surgical crew.

All trephined patients who died or evolved without symptoms or signs compatible to ST were excluded from this patient case series. Epidemiological data, reason to decompression, time to decompressive craniectomy, symptoms and signs compatible to ST, and time to cranioplasty may be seen in Table.

All patients included in this study were routinely submitted to laboratory essays, radiographic exams and videoelectroencephalography to exclude others causes of neurological impairment. All were submitted to brain MRI scan, with small coronal fat-suppression cuts, in order to calculate the optic nerve sheath diameter, before and after cranioplasty. Cranioplasty was routinely planned after 3 months from decompression.

Our goal was to determine the usefulness of the asymmetric optic nerve sheath diameter in craniectomy patients as a diagnostic signal and as a good outcome factor after cranioplasty.

\section{RESULTS}

Among these 5 patients, all have developed neurological deterioration after unilateral decompressive craniectomy at a mean follow-up of 6 months, including orthostatic headache, diplopia, contralateral hemiparesis, gait ataxia, excessive sleepiness up to periods of minimal consciousness. All patients had their symptoms reversed by placing then into Trendelenburg position. At ectoscopy all patients presented sinking skin flap at the site of craniectomy. On radiologic examination all presented paradoxical herniation.

After ruling out all other possible disorders, all patients have been presumably diagnosed with ST.

However, on MRI scanning only two patients (patients $\mathrm{B}$ and $\mathrm{E}$ ) presented an asymmetric optic nerve sheath diameter (ONSD), being the ONSD larger at the side of craniectomy (Figure 1). Surprisingly these two patients had a marked neurological improvement after cranioplasty, with normalization of the ONSD and disappearance of the brain shift a day after procedure (Figure 2), becoming independent a week after procedure.

The others three patients (patients A, C and D), who had a symmetric ONSD at MRI, have also improved their consciousness level, but in a very slowly way, becoming independent after a few months.

Table 1. Epidemiological and clinical data from patients submitted to decompressive craniectomy (DC), symptoms and signs suggestive of "syndrome of the trephined" (ST), and time to cranioplasty.

\begin{tabular}{|c|c|c|c|c|c|c|c|}
\hline Patient & Age & Gender & Diagnosis & Time to DC & ST symptoms & ST signs & Time to cranioplasty \\
\hline A & $23 y$ & $M$ & TBI & $24 \mathrm{~h}$ & Headache, ALC and diplopia & Paradoxical herniation & $3 \mathrm{~m}$ \\
\hline B & $67 y$ & M & $\mathrm{RCSH}$ & $1 \mathrm{~m}$ & ALC, hemiparesis & $\begin{array}{l}\text { Sinking skin flap, } \\
\text { paradoxical herniation }\end{array}$ & $3 \mathrm{~m}$ \\
\hline C & $53 y$ & $\mathrm{~F}$ & AMCHS & $12 \mathrm{~h}$ & ALC, ataxia & Paradoxical herniation & $4 \mathrm{~m}$ \\
\hline D & $19 y$ & M & $\mathrm{TBI}$ & $5 d$ & ALC & $\begin{array}{l}\text { Sinking skin flap, } \\
\text { paradoxical herniation }\end{array}$ & $3.5 \mathrm{~m}$ \\
\hline E & $58 y$ & M & AMCHS & $16 \mathrm{~h}$ & ALC & Paradoxical herniation & $3 \mathrm{~m}$ \\
\hline
\end{tabular}

y: years-old; M: male; F: female; TBI: traumatic brain injury; RCSH: recurrent chronic subdural hematoma; AMCHS: acute "malignant" cerebral hemispheric stroke; h: hours; m: months; d: days; ALC: altered levels of consciousness. 
Patients harboring the ST with symmetric ONSD needed statistically more time to become independent after cranioplasty than patients with asymmetric ONSD (mean time of 38 days vs 8 days, t-test, $\mathrm{p}<0,05)$.

\section{DISCUSSION}

It is well known the usefulness of the decompressive craniectomy in the treatment of refractory intracranial pressure, but not without significant complications. One of the harmful complications is surely the "syndrome of the trephined". Up to now there was no diagnostic tool or prognostic factor capable to make a tailored diagnosis and to predict a good outcome.
The measurement of the ONSD is an important indirect method to suppose or diagnose increased levels of intracranial pressure (ICP). The ultrasonographic visualization of the optic nerve is feasible, costless, and world-wide applied to diagnose intracranial hypertension ${ }^{16,17}$.

By its time, the use of MRI to detect raised ICP is a more recent method. It seems to bring more precision to the measurement of the ONSD. ONSD is strongly related to ICP, a finding that reflects distension of the nerve sheath during increases in CSF pressure. On T2-weighted sequences, CSF exhibits a high signal (white), whilst fat and gray matter appear as light grey $^{18}$. The perioptic CSF is surrounded by orbital fat. Contrast between CSF and orbital fat can be improved with fat suppression, increasing the image resolution for the ONSD measurement ${ }^{18,19}$.
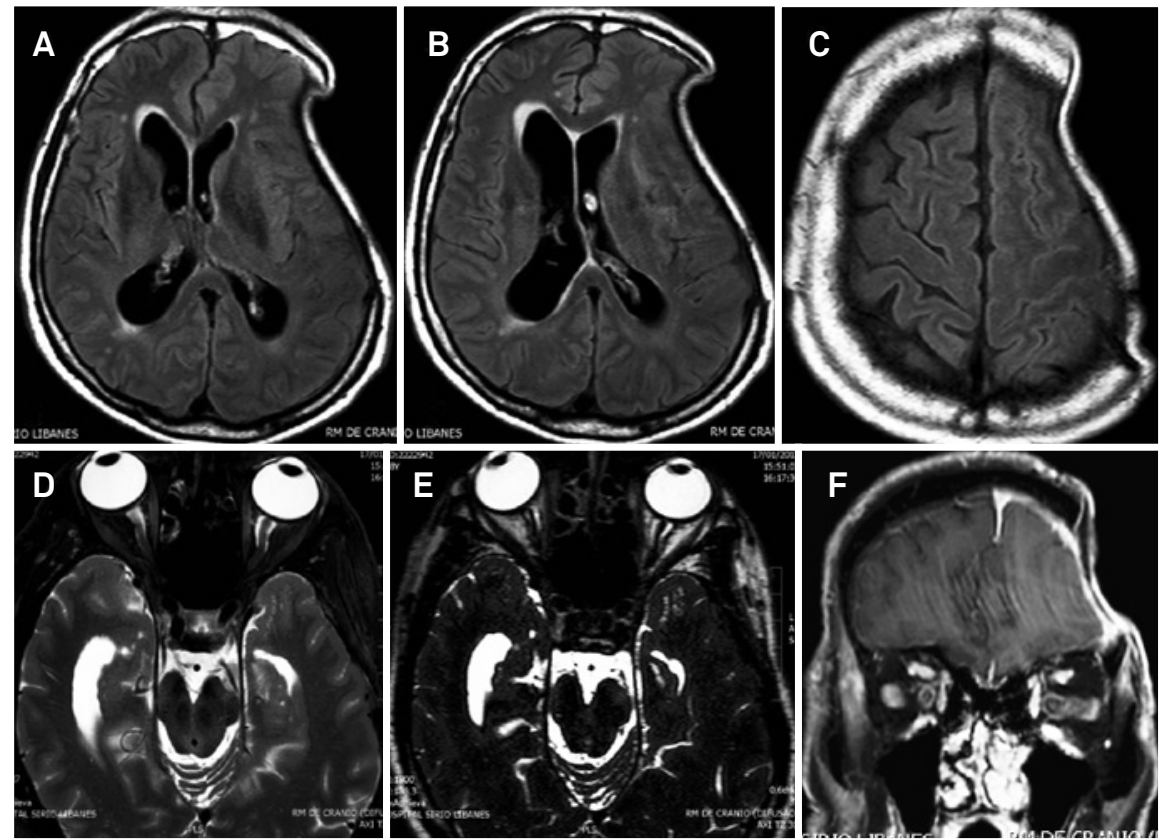

Figure 1. (A-B) Axial T1-weighted MRI, FLAIR sequence, showing sinking skin flap at the left side of craniectomy, paradoxica herniation to the right side, and subfalcine herniation; (C) Axial T1 MRI, cerebral sulci effacement at the left side; (D-E) Axial T2-weighted MRI, asymmetry of the optic nerve sheath diameter (ONSD), being larger at the left side (6.8 mm) vs right side (5.8 mm); (F) Coronal fat-suppressed T2-weighted MRI, asymmetric ONSD.
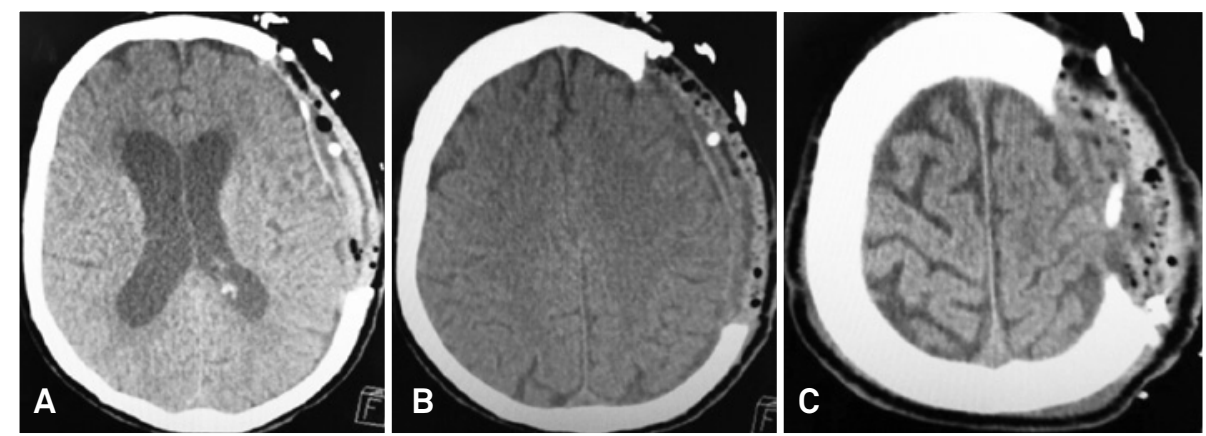

Figure 2. Axial brain CT one day after methyl methacrylate cranioplasty of the trephined patient from Figure 1. (A-B) Disappearance of the brain shift and subfalcine herniation; (C) Recovery from the cerebral sulci effacement. 
Table 2. Optic nerve sheath diameter (ONSD) at the side of cranioplasty from patients harboring the "syndrome of the trephined", pre and post cranioplasty, and Glasgow Outcome Scale (GOS) one week and two months after cranioplasty.

\begin{tabular}{lcccc} 
Patient & ONSD pre & ONSD post & GOS 1-w & GOS 2-m \\
\hline A & $5.6 \mathrm{~mm}$ & $5.6 \mathrm{~mm}$ & 3 & 4 \\
B & $6.8 \mathrm{~mm}$ & $5.8 \mathrm{~mm}$ & 5 & 5 \\
C & $4.8 \mathrm{~mm}$ & $4.8 \mathrm{~mm}$ & 4 & 5 \\
D & $5.4 \mathrm{~mm}$ & $5.4 \mathrm{~mm}$ & 3 & 5 \\
E & $6.4 \mathrm{~mm}$ & $5.6 \mathrm{~mm}$ & 5 & 5 \\
\hline
\end{tabular}

w: week; m: months.

The most useful clinical message derived from current data may be summarized as followed: an ONSD less than $5.3 \mathrm{~mm}$ is unlikely to be associated with raised ICP; an ONSD above $5.82 \mathrm{~mm}$ indicates that the probability of raised ICP is $90 \%{ }^{18,19}$.

In our series of trephined patients, those that presented ONSD asymmetry (patients B and E) had at the side of craniectomy an ONSD greater than $6 \mathrm{~mm}$ (strongly suggesting raised ICP), and had their diameter decreased to normal values one day after cranioplasty, see Table 2. Surprisingly those two patients evolved better than patients without ONSD asymmetry, becoming independent (Glasgow Outcome Scale 5) just one week after cranioplasty (Table 2).

That ONSD asymmetry may be explained by local changes of the CSF hydrodynamics, resulting in distension of the nerve sheath ipsilateral to the craniectomy side. This distension by its turn may reflect that the intracranial pressures finally have been overwhelmed by the forces of atmospheric pressure and gravity. Correction of this distension just after cranioplasty may indicate the recovery from the CSF hydrodynamics and normalization of intracranial pressures from a cranium converted back to a 'closed box' system.

It is presumed that the ONSD asymmetry may be used as a prognostic factor in patients with ST following the cranioplasty, but the small number of patients enrolled in this study and the rarity of this disease may compromise further conclusions. Larger prospective studies are needed and should dissolve major doubts.

In conclusion, the "syndrome of trephined" is a rare late complication after decompressive craniectomy. It is presumed that the presence of an asymmetric ONSD at MRI of trephined patients is an independent factor of good outcome after cranioplasty.

\section{References}

1. Gadde J, Dross P, Spina M. Syndrome of the trephined (sinking skin flap syndrome) with and without paradoxical herniation: a series of case reports and review. Del Med J 2012;84:213-218.

2. Honeybul S, Ho KM. Long-term complications of decompressive craniectomy for head injury. J Neurotrauma 2011;28:929-935.

3. Yang XF, Wen L, Shen F, et al. Surgical complications secondary to decompressive craniectomy in patients with a head injury: a series of 108 consecutive cases. Acta Neurochir (Wien) 2008;150:1241-1248.

4. Honeybul S. Complications of decompressive craniectomy for head injury.J Clin Neurosci 2010;17:430-435.

5. Stiver SI. Complications of decompressive craniectomy for traumatic brain injury. Neurosurg Focus 2009;26:7.

6. Akins PT, Guppy KH. Sinking skin flaps, paradoxical herniation, and external brain tamponade: a review of decompressive craniectomy management. Neurocrit Care 2008;9:269-276.

7. Choi JJ, Cirivello MJ, Neal CJ, Armonda RA. Paradoxical herniation in wartime penetrating brain injury with concomitant skull-base trauma.J Craniofac Surg 2011;22:2163-2167.

8. Mokri B. Orthostatic headaches in the syndrome of the trephined: resolution following cranioplasty. Headache 2010;50:1206-1211.

9. Bijlenga P, Zumofen D, Yilmaz H, Creisson E, de Tribolet N. Orthostatic mesodiencephalic dysfunction after decompressive craniectomy. J Neurol Neurosurg Psychiatry 2007;78:430-433.

10. Gottlob I, Simonsz-Tòth B, Heilbronner R. Midbrain syndrome with eye movement disorder: dramatic improvement after cranioplasty. Strabismus 2002;10:271-277.
11. Stiver SI, Wintermark M, Manley GT. Reversible monoparesis following decompressive hemicraniectomy for traumatic brain injury. J Neurosurg 2008;109:245-254.

12. Chalouhi N, Teufack S, Fernando Gonzalez L, Rosenwasser RH, Jabbour PM. An extreme case of the syndrome of the trephined requiring the use of a novel titanium plate. Neurologist 2012;18:423-425.

13. Janzen C, Kruger K, Honeybul S. Syndrome of the trephined following bifrontal decompressive craniectomy: implications for rehabilitation. Brain Inj 2012;26:101-105.

14. Fodstad H, Love JA, Ekstedt J, Fridén H, Liliequist B. Effect of cranioplasty on cerebrospinal fluid hydrodynamics in patients with the syndrome of the trephined. Acta Neurochir (Wien) 1984;70:21-30.

15. Dujovny M, Fernandez P, Alperin N, Betz W, Misra M, Mafee M. Postcranioplasty cerebrospinal fluid hydrodynamic changes: magnetic resonance imaging quantitative analysis. Neurol Res 1997;19:311-316.

16. Dudea SM. Ultrasonography of the eye and orbit. Med Ultrason 2011;13:171-174.

17. Foster T, Tayal VC, Saunders T, Norton J. Emergency ultrasound optic nerve sheath measurement to detect increased intracranial pressure in head injury patients: preliminary study of interobserver variability in normal human subjects. Acad Emerg Med 2003;10:487-488.

18. Welling LC, Figueiredo EG, Machado FS, Andrade AF, Guirado VM, Teixeira MJ. Noninvasive evaluation of intracranial hypertension? Is there a gold standart? Arq Bras Neurocir 2012;31:224-230.

19. Geeraerts T, Newcombe VF, Coles JP, et al. Use of T2-weighted magnetic resonance imaging of the optic nerve sheath to detect raised intracranial pressure. Crit Care 2008;12:114. 